\title{
Metallurgical Aspects of Laser Surface Processing of PM Cr-V Ledeburitic Steel
}

\author{
Peter Jurči, Jiři Cejp, and Jan Brajer \\ Faculty of Mechanical Engineering, Czech Technical University in Prague, Karlovo Nám. 13, 12135 Prague 2, Czech Republic \\ Correspondence should be addressed to Peter Jurči, p.jurci@seznam.cz
}

Received 13 July 2010; Revised 23 November 2010; Accepted 6 December 2010

Academic Editor: J. Dutta Majumdar

Copyright () 2011 Peter Jurči et al. This is an open access article distributed under the Creative Commons Attribution License, which permits unrestricted use, distribution, and reproduction in any medium, provided the original work is properly cited.

The Vanadis 6 ledeburitic-type steel was laser surface remelted. Microstructural changes and hardness in laser affected material were investigated using light microscopy, SEM, and EDS-microanalysis. It was found that the laser surface melting and subsequent rapid solidifying led to softening of the material, due to presence of retained austenite. The melting of the material begins with the transformation of $\mathrm{M}_{7} \mathrm{C}_{3}$-carbide into a liquid and finishes via the dissolution of primary solid solution grains. The solidification proceeded in a reverse manner while the eutectics became often so-called degenerous form.

\section{Introduction}

Over the last three decades, the laser surface processing of metals became an important industrial technique used in variety of applications. High power densities delivered to the workpieces can produce fully austenitized or entirely melted and resolidified regions while the process of the treatment can be completed in few seconds [1].

Many laboratory examinations indicated that the laser surface melting can be a very promising technique in a variety of industrial applications. However, technical application of the laser surface melting is currently limited due to several causes. The first one is the economical aspectmostly high initial costs for the laser equipment. The second problem is connected with the nature of common metallic materials used for the workpieces manufacturing. Since the material undergoes rapid heating and cooling during the laser thermal cycle, coarse structural constituents such as thick pearlitic lamellae or carbides and clusters can make serious obstacles in the results of treatment. Other important difficulty is connected with the applications, when multiple traces are needed to process larger surface areas. In these cases, annealing effects can take place in adjacent laser traces.

The laser surface melting of ledeburitic steels (Cr-, CrV-cold work tool steels, high speed steels) has been considered as a promising technique many years ago. It was believed that the surface remelting can form a "refined ascast microstructure" in thin near-surface region while the microstructure of the core material remains unaffected. Refined "as-cast microstructure", as assumed, would more effectively withstand the degradation processes connected with the use of tools, like abrasive and adhesive wear, since it contains very hard carbides creating continuous networks. The core material, on the other hand, consists of the matrix with uniformly distributed fine carbide particles, which ensures an appropriate toughness of the steel.

Metallurgical aspects of laser surface melting of various ledeburitic steels were investigated by many authors. It has been found that for laser remelted M2-type high speed steel, refined dendritic or cellular morphology of primary phase is typical $[1,2]$. In addition, our pioneer work [3] confirmed that the solidification of the material finishes by eutectic transformation. Based on the fact that the molten microvolume of the material undergoes the rapid solidification effect, eutectics often freeze irregularly, in a so-called "degenerous" manner. As reported elsewhere, the eutectics can also contain metastable and intermediate phases instead of stable carbides for given systems [4].

Typical cooling rates in laser surface melting were estimated to range between $10^{3}$ and $10^{6} \mathrm{Ks}^{-1}$. Such a high cooling rate induces considerable alterations in the mechanism of crystallization. For most types of high speed steels, for 


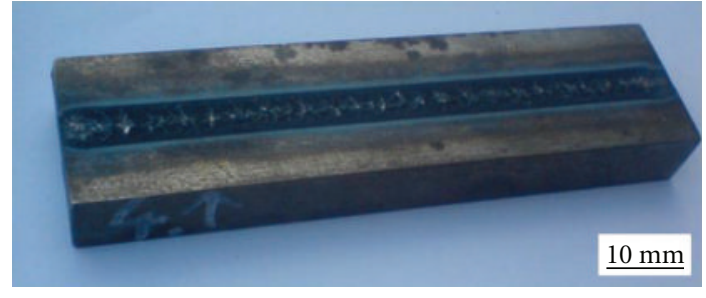

FIgURE 1: Specimen irradiated by laser.

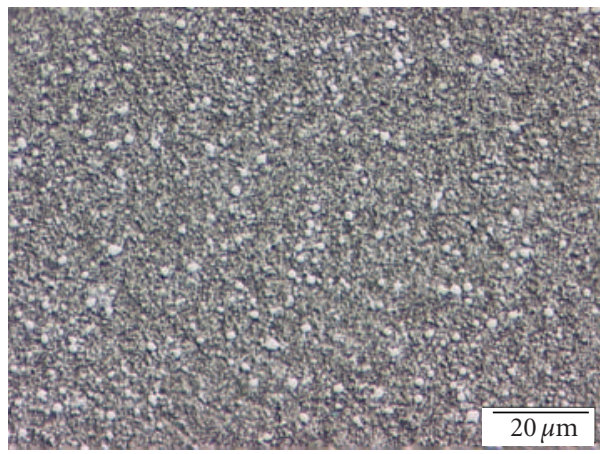

FIGURE 2: Light micrograph showing the substrate material.

instance, the primary crystallization proceeds by peritectic reaction. As reported by Nizhnikowskaya [5], the peritectic reaction in high speed steels proceeds completely only when the cooling does not exceed $10^{3} \mathrm{Ks}^{-1}$. At higher cooling rates, the $\delta$-ferrite is conserved in the microstructure of solidified metal. This makes a considerable softening of the material, not only after remelting but also after tempering to the maximum of secondary hardness $[6,7]$. Therefore, the high speed steels cannot be considered as suitable materials for the laser surface melting. Other negative aspects were published by Colaço and Vilar $[8,9]$. They found out that the laser melted and rapidly resolidified material can contain a high portion of the retained austenite.

One can expect that the laser remelted materials would have generally increased hardness compared to conventionally quenched and tempered steel. The reason is that owing to the rapid solidification, extended solid solutions can be formed that can have a positive effect upon the hardness. For the ledeburitic steels, however, the situation seems to be more complex and a general statement on the behaviour of laser remelted and rapidly solidified materials does not exist. At least, above-mentioned changes in the mechanism of primary crystallization of high speed steels can influence the hardness negatively. Also the presence of the retained austenite has an undesirable effect upon the hardness. But, as found out by Colaço and Vilar [9], and independently also by the main author of this paper [10], the softening of the material due to the retained austenite can be completely eliminated by subsequent tempering if the alloy has an appropriate chemical composition.

The laser surface remelting of $\mathrm{Cr}-\mathrm{V}$ ledeburitic steels, and its consequence upon the structure and properties was not investigated seriously yet. The goal of the paper is to provide the first attempt on the evaluation of surface remelting upon an example of PM cold work tool steel Vanadis 6.

\section{Experimental}

The experimental material was the PM ledeburitic steel Vanadis 6 with nominally (in wt $\%$ ) $2.1 \%$ C, $1.0 \% \mathrm{Si}, 0.4 \%$ $\mathrm{Mn}, 6.8 \% \mathrm{Cr}, 1.5 \% \mathrm{Mo}, 5.4 \% \mathrm{~V}$, and $\mathrm{Fe}$ as balance. Asreceived material after soft anneal had a hardness of 284 HV10. Plate-like specimens with $70 \mathrm{~mm}$ in length, $18 \mathrm{~mm}$ in width, and $8 \mathrm{~mm}$ in thickness were mechanically milled and fine ground to a final surface roughness $R_{a}=0.2-0.3 \mu \mathrm{m}$.

The specimens were then subjected to standard heat treatment. The heat procedure included the vacuum austenitizing up to final temperature of $1050^{\circ} \mathrm{C}$, nitrogen gas quenching at 5 bars pressure and double tempering, each cycle at $550^{\circ} \mathrm{C}$ for 1 hour. After each tempering cycle, the material was air-cooled down to an ambient temperature. Resulting hardness of heat treated specimens was $700 \mathrm{HV} 10$.

Laser processing has been performed using the GSI LUMONICS $701 \mathrm{H} \mathrm{Nd:YAG-laser} \mathrm{equipment,} \mathrm{with} \mathrm{the}$ wavelength of the irradiation of $1064 \mathrm{~nm}$, operating in a continuous regime. The standard output power of the laser was $450 \mathrm{~W}$. The laser beam was focused to $50 \mathrm{~mm}$ over the specimen surface. The relative beam speed on the specimen's surface was $80 \mathrm{~mm} / \mathrm{min}$. Specimens were laser processed in a longitudinal direction, Figure 1.

Irradiated material was prepared for the microstructural analysis. Cross-sectional samples were ground, polished, and etched by 3\% Nital reagent. Light and scanning electron microscopy (SEM) have been used for the investigations. The standard accelerating voltage of SEM was $15 \mathrm{kV}$ for the microstructural investigations. For better understanding of the nature of structural constituents, also the energydispersive spectroscopy (EDS) analysis and mapping have been done. But, the acceleration voltage of SEM was at strictly reduced to $1 \mathrm{kV}$, to avoid too deep penetration of electron beam, and to enable more accurate analysis.

Quantification of the retained austenite volume fraction has been done using the NIS-elements software. Standard light microscope magnification was 800x. The measurements were made in various places of cross-sectional samples, in the direction from the surface towards the core material. Five measurements were done on each place. From obtained results, the mean value and the standard deviations were calculated.

Hardness measurements have been made throughout the laser influenced material using a Vickers hardness tester, at a load of $0.3 \mathrm{~kg}$ (HV 0.3). The hardness maps of cross-sections of laser traces were then constructed, enabling us to compare the microstructure to the hardness in any of the typical laser influenced regions.

\section{Results and Discussion}

Light micrograph, Figure 2, shows the microstructure of the substrate steel after quenching and tempering to a hardness of $700 \mathrm{HV}$. The material consists of the martensitic matrix 


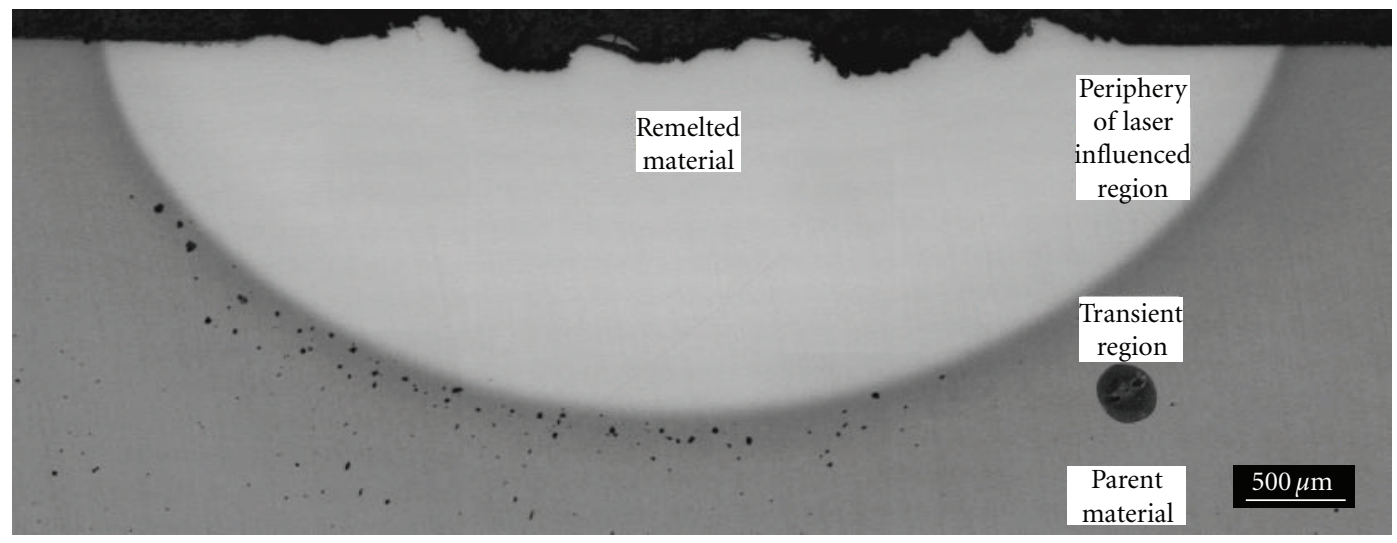

FIgURE 3: Cross-sectional light micrograph showing the overview of laser spot.

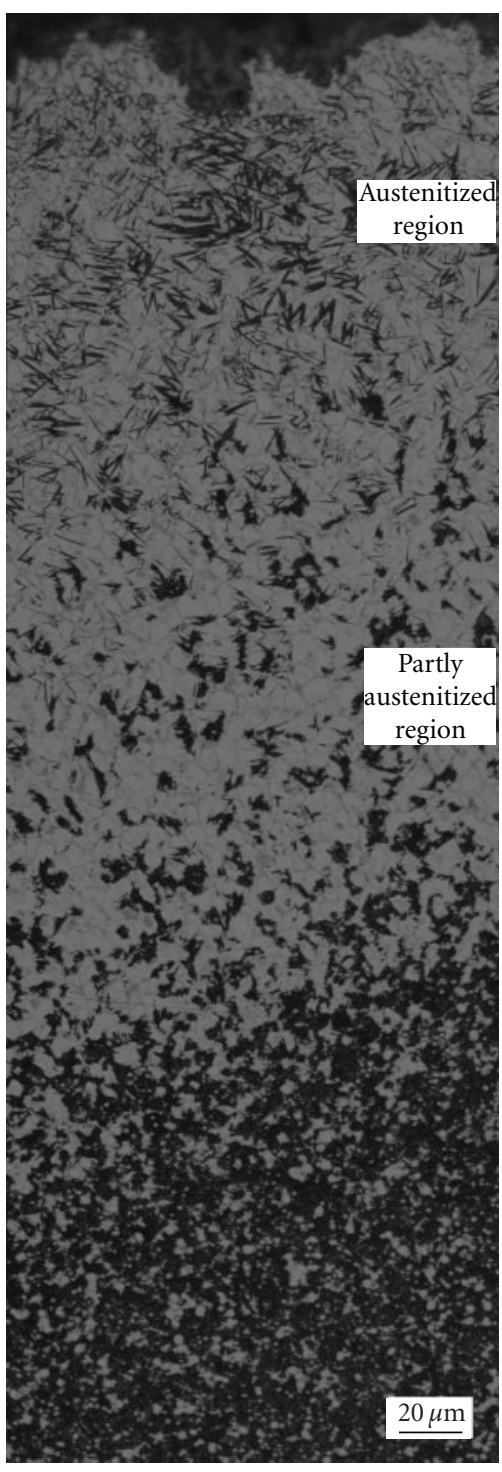

FIGURE 4: Cross-sectional light micrograph showing the periphery of laser influenced spot. and fine (size of several microns) globular carbide particles. Previous experimental investigations revealed that the carbides are of two types-vanadium rich $\mathrm{MC}$-phase and chromium-rich $\mathrm{M}_{7} \mathrm{C}_{3}$-phase [11].

The total influenced depth and width by laser were measured to be 1.7 and $5 \mathrm{~mm}$, respectively, Figure 3. It is clearly shown that the surface quality of remelted material is poor because the processing led to increased surface roughness in the centre of the spot. Similar facts were reported by Ramous [12]. He stated that problems with the surface quality, connected with the needs of additional costs for surface finishing, are one of the limiting factors of industrial use of the laser surface melting technique. For further investigations, therefore, much more careful control of the laser parameters is necessary to obtain a good smooth surface. Other inhomogeneities (pores, cracks) were neither found in the laser spot nor in the vicinity of that.

Figure 4 shows the cross-sectional micrograph of the periphery of laser irradiated region. There are no symptoms of the remelting of the material. Close to the surface, there is a region that underwent rapid austenitizing up to a very high temperature and subsequent rapid cooling down, due to strong thermal flux into the core material. The microstructure consists of small portion of martensite, high portion of retained austenite and undissolved carbides. In between, there is the material, which also underwent the austenitizing during the laser irradiation. But, the processing time was not long enough for the complete transformation of the structure into the austenite. Therefore, the "islands" of nonaustenitized material can be found. The number and size of these formations increase as the distance from the surface increases. Parent material was not affected by laser beam and the structure consisted of tempered martensite and carbides, as developed by previous furnace treatment.

The central region of laser spot contained remelted zone close the surface, Figure 5. This zone can be divided into two characteristic regions. The first one, having a thickness of only several tens of microns, forms very tiny layer on the surface. The structure contained primary austenite cells and 
TABLE 1: Results of retained austenite volume fraction measurements.

\begin{tabular}{lccccccc}
\hline Depth below the surface $(\mathrm{mm})$ & 0.1 & 0.2 & 0.3 & 0.4 & 0.5 & 0.6 & 0.7 \\
\hline Central region & $82 \pm 2$ & $81 \pm 4$ & $67 \pm 7$ & $63 \pm 4$ & $39 \pm 5$ & $16 \pm 3$ & $17 \pm 3$ \\
Periphery & $61 \pm 8$ & $63 \pm 6$ & $57 \pm 9$ & $49 \pm 4$ & $30 \pm 4$ & $18 \pm 3$ & $15 \pm 3$ \\
\hline
\end{tabular}

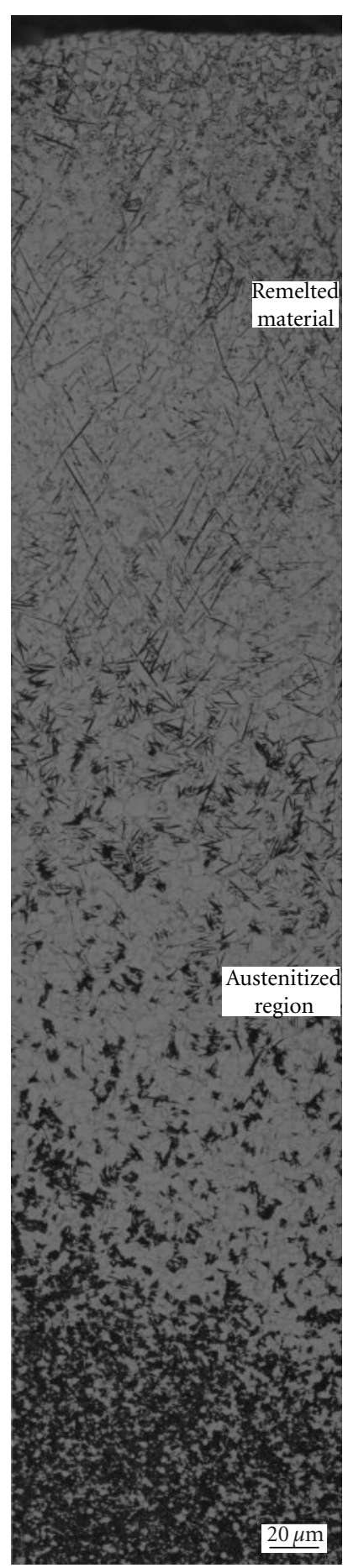

FIGURE 5: Cross-sectional light micrograph showing the central region of laser-influenced spot. continuous eutectic network along them. The second typical region was larger. It underwent only partial melting. As a result, some of structural constituents were not influenced significantly by the laser processing. The microstructure of this region contained small amount of martensite and high portion of retained austenite. In the intergranular spacings, there is laser melted material, in a form of continuous network. Below the remelted zone, there is the austenitized and quenched region, having the microstructure similar to that described in one of above-mentioned paragraph.

Results of quantitative structural analysis are summarized in Table 1. The volume fraction of retained austenite exceeded clearly $60 \%$ in laser remelted and partially remelted material. But, also in the material austenitized to a very high temperature, see also upper part of Figure 4, the volume fraction of retained austenite over $50 \%$ has been identified. Towards the core material, however, the amount of retained austenite decreased to a "normal value", ranging between $15-20 \%$, which is typical for standardly furnace processed material Vanadis 6.

SEM micrograph, Figure 6, made from laser melted and rapidly solidified material shows that the microstructure is formed by the matrix and two morphological types of carbides. The matrix is mostly austenitic, but the presence of some portion of martensitic needles is also evident. EDS-map in Figure 7(a) shows that the first carbide type is a chromium rich phase. Based on our previous results $[11,13,14]$ it can be assumed that chromium rich phase is the $\mathrm{M}_{7} \mathrm{C}_{3}$-carbide. These particles underwent evidently partial melting and during the freezing, they formed eutectics, Figures 6 and $7(\mathrm{a})$, respectively. The second type of carbides is the MC-phase, Figures 6 and 7(b), respectively. However, it contains also a small portion of chromium; see Figure $7(\mathrm{a})$. This finding is well consistent with other observations $[15,16]$, where up to $10 \mathrm{wt} \% \mathrm{Cr}$ was found in MC-carbides. Globular shape of these particles, as formed by the manufacturing of the material indicates that they did not undergo melting during the laser processing of the material and remain almost completely unaffected.

For better clarification of the behaviour of laser irradiated material, previous experimental investigations upon the quaternary $\mathrm{Fe}-\mathrm{C}-\mathrm{Cr}-\mathrm{V}$ alloys have to be taken into consideration. These experiments revealed that $\mathrm{Cr}-\mathrm{V}$ ledeburitic steels solidify via complex mechanism where at least two eutectic transformations take place $[13,14]$. The first transformation proceeds at higher temperature. As a result, needle-like mixture based on the MC-phase is formed. In the laser affected region, Figure 6, this mixture was not appeared. It seems that the temperature in dominant part of the laser spot was not high enough to enable complete melting of the 


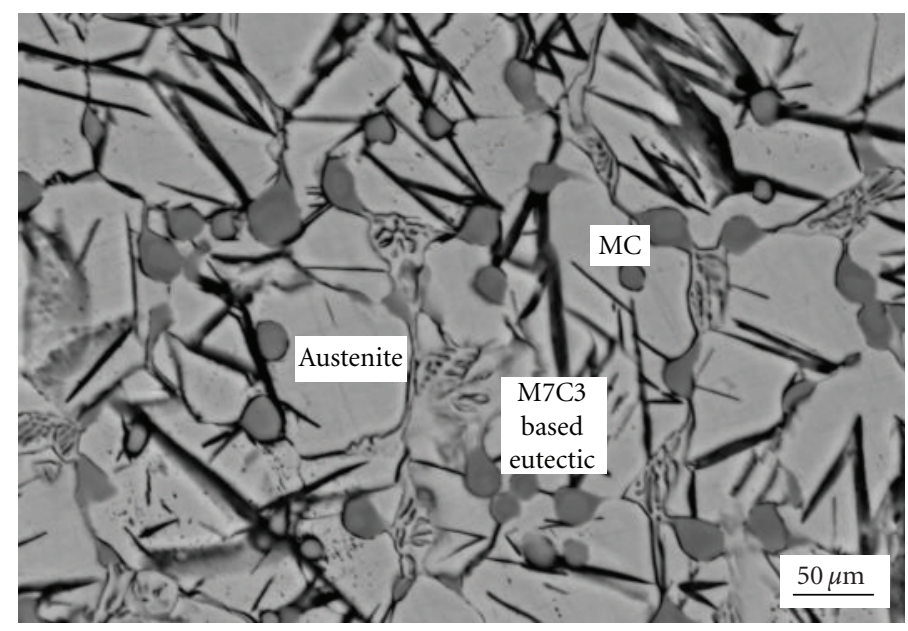

FIGURE 6: SEM micrograph showing the microstructure of remelted material.

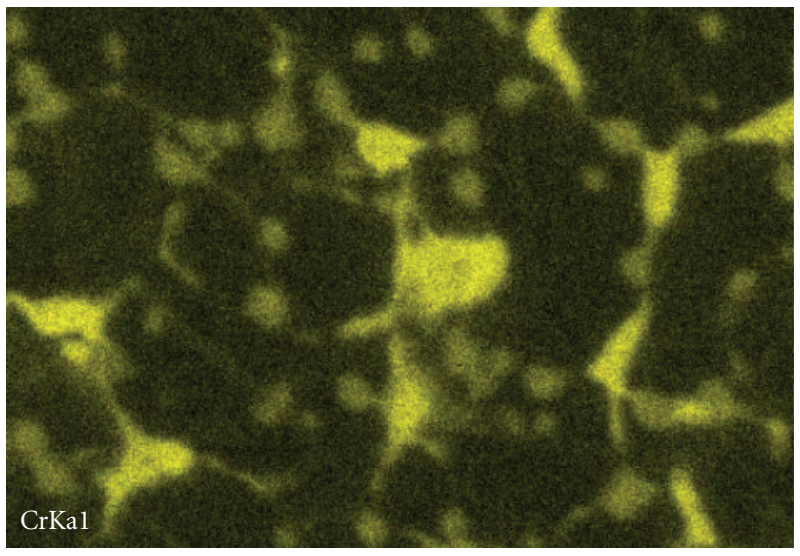

(a)

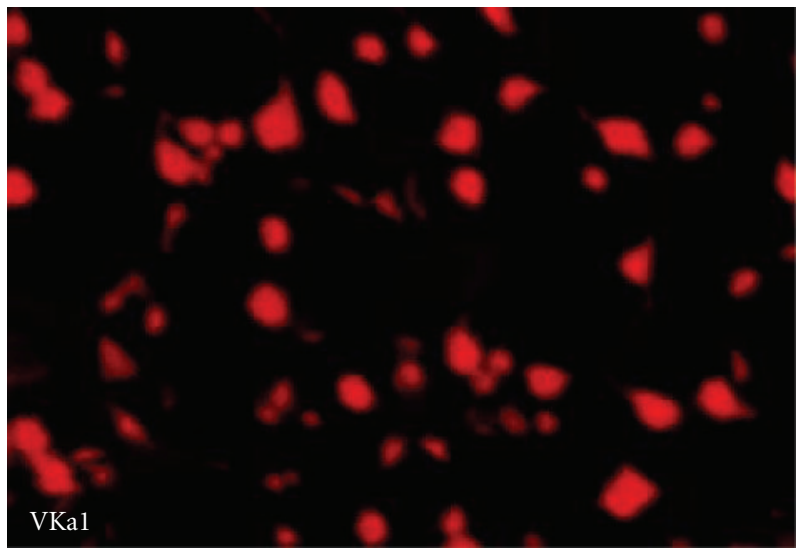

(b)

FIgURE 7: EDS maps of chromium and vanadium distribution from the material shown in Figure 6.

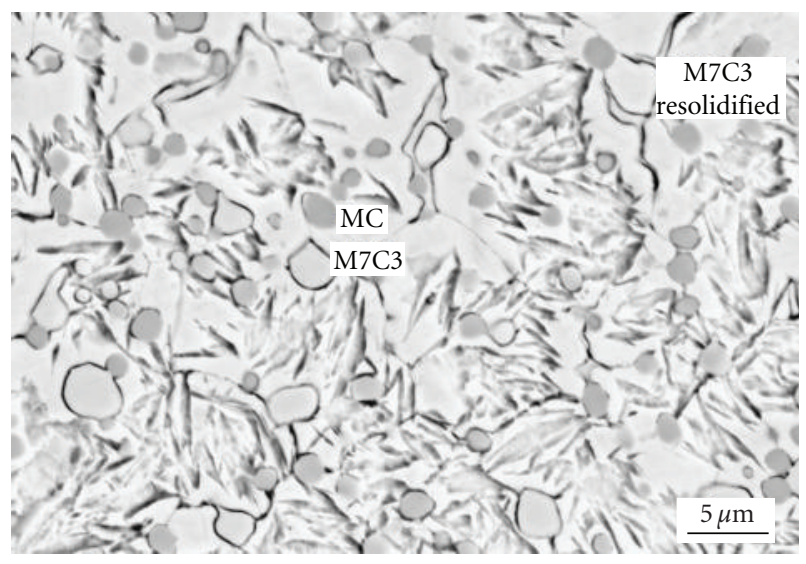

FIGURE 8: SEM micrograph showing the microstructure of interface region between remelted and solid state hardened zone.

material. The MC-carbides remain practically unaffected and retained globular shape, resulting from the manufacturing route of the steel.
During the solidification of $\mathrm{Cr}-\mathrm{V}$ ledeburitic steels, the second eutectic mixture based on the $\mathrm{M}_{7} \mathrm{C}_{3}$-carbide is formed at lower temperature $[13,14]$. It appears in a bladelike form in pure $\mathrm{Fe}-\mathrm{C}-\mathrm{Cr}$ system or if the vanadium content is sufficiently low in the alloy. At higher vanadium content, however, the morphology of this phase changes to skeleton. This is also the case of laser melted and resolidified Vanadis 6 steel, as clearly visible on the SEM micrograph, Figure 6.

Close to the melting boundary it is evident how the $\mathrm{M}_{7} \mathrm{C}_{3}$-carbides began to melt, Figures 8 and 9 (a). If the temperature was close to the solidus of the material, then this phase transformed into a liquid in a very limited extent, and the second part remained almost unaffected. After the laser processing, the $\mathrm{M}_{7} \mathrm{C}_{3}$-phase solidified rapidly and formed semicontinuous formations along the grain boundaries. Since the temperature was not high enough for melting of other phases (solid solution, MC-phases), they remain almost unaffected. The formations along the primary grains can thus be considered as so-called "degenereous eutectic structure", containing only one phase- $\mathrm{M}_{7} \mathrm{C}_{3}$, Figures 8 and 9. 


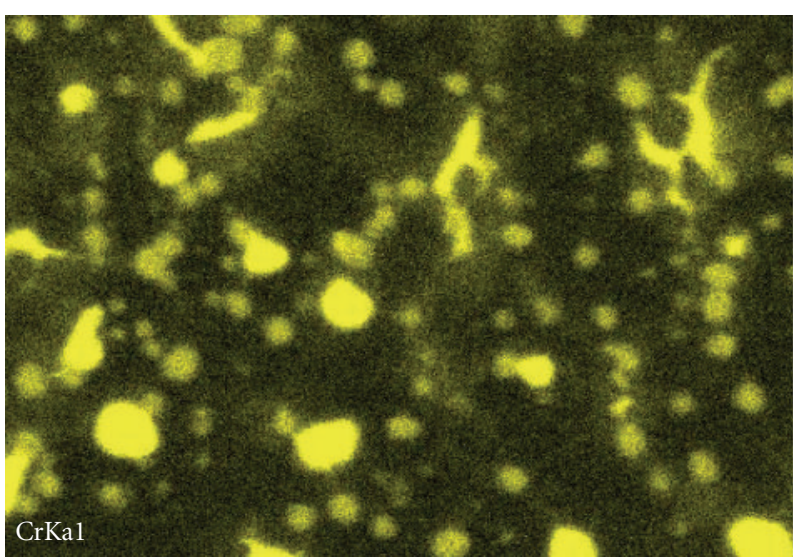

(a)

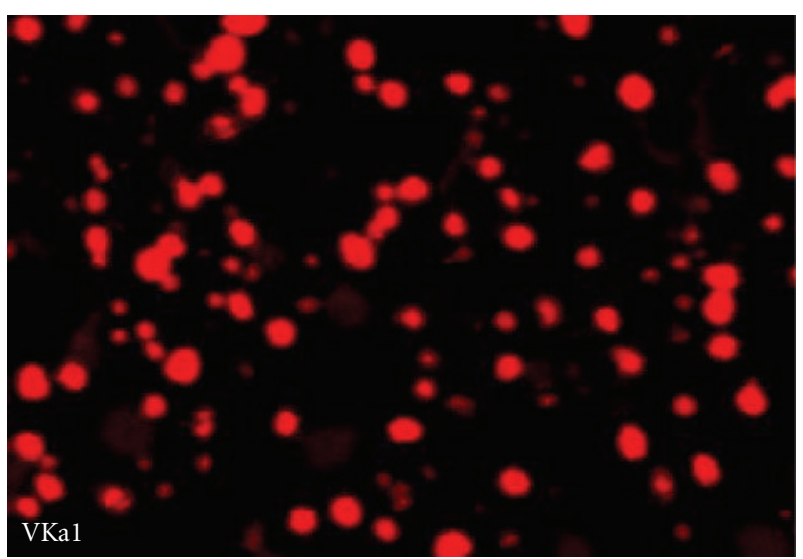

(b)

FIgURE 9: EDS maps of chromium and vanadium distribution from the material shown in Figure 8.
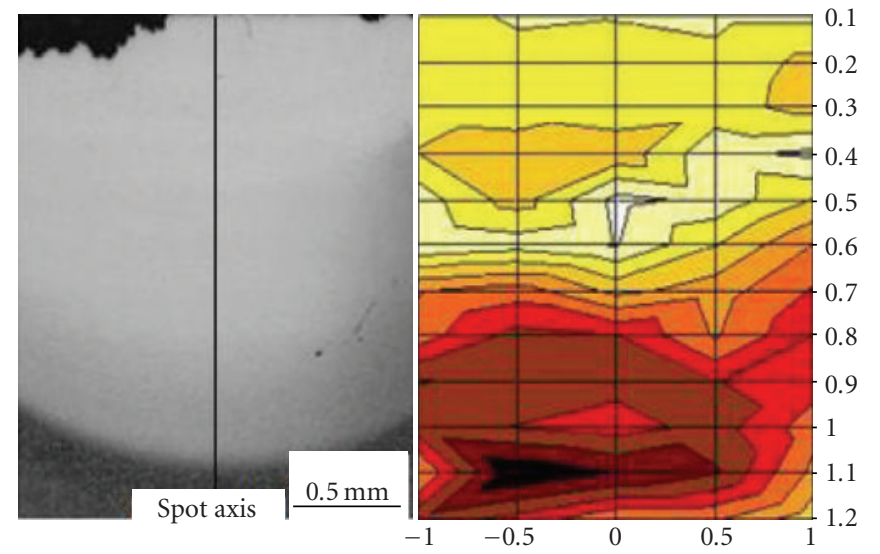

Hardness HV 0.3

Distance from the laser spot axis $(\mathrm{mm})$

$\begin{array}{ll}\square 670-700 & \square 520-550 \\ \square 640-670 & \square 490-520 \\ \square 610-640 & \square 460-490 \\ \square 580-610 & \square 430-460 \\ \square 550-580 & \square 400-430\end{array}$

FIgURE 10: Hardness distribution throughout the laser influenced material.

The hardness of laser remelted and partially remelted material ranged between 490 and $580 \mathrm{HV}$ 0.3, Figure 10 . Region with such values of hardness reaches down to approximately. $0.5 \mathrm{~mm}$ from the surface. Around, there is a slightly softer material, having hardness between 400 and $460 \mathrm{HV}$ 0.3. The periphery of laser-influenced region, which was completely austenitized but not overheated, had the highest hardness. It exceeded $600 \mathrm{HV} 0.3$, but in some cases it was higher than $700 \mathrm{HV} 0.3$. The hardness of the transient region, located in close vicinity of the laser spot, exhibited considerably lower hardness compared to fully austenitized material of the periphery of the laser spot. The hardness values ranged around $450 \mathrm{HV} 0.3$.

The behaviour of the laser-influenced material with respect to the hardness can be explained as follows: the remelted material contains primary grains of the austenite, small portion of the martensite, MC-carbides (that mostly did not undergo melting), and $\mathrm{M}_{7} \mathrm{C}_{3}$-carbides (less or more transferred into a liquid phase during processing). It is naturally to expect that this structure has reduced hardness compared to no laser influenced material because two processes were probably happening during the laser processing. The first one is the extension of solid solutions, due to the rapid solidification effect (hardness increase). The second phenomenon is connected with extremely high saturation of as-solidified austenite with carbon and alloying elements and results in high portion of retained austenite in resolidified material of laser spot; see also Table 1 . The final hardness of remelted material is then a result of the competition between these two processes whereas it is evident that the softening, caused by extremely high retained austenite volume fraction, becomes dominant. It should also 


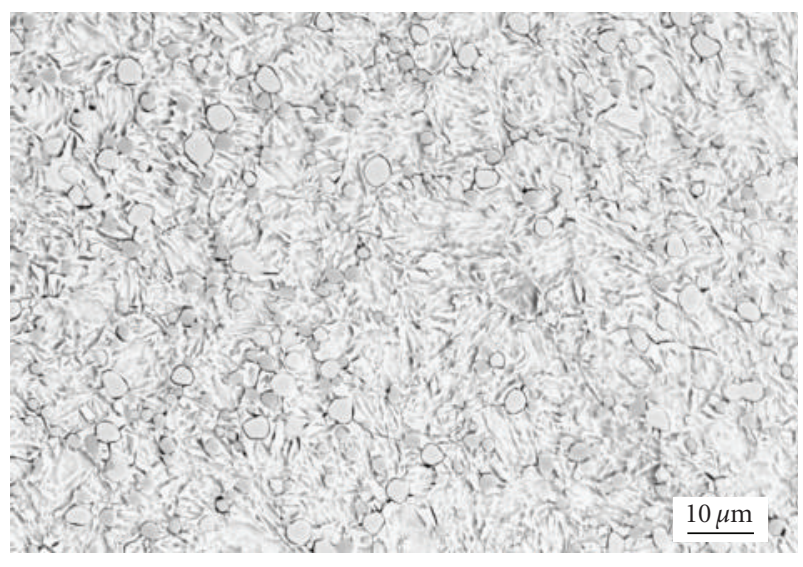

FIGURE 11: SEM micrograph showing the microstructure of solid state hardened zone.

be noticed that the cooling rates in laser processing cannot exceed $10^{5} \mathrm{Ks}^{-1}$ for common metallic materials. Therefore, the microstructural effects are reduced only to the grain refinement and slight extension of solid solutions, which is insufficient to compensate the softening effect of highly retained austenite content.

One possible way how to increase the hardness of laser remelted material is a subsequent tempering. The tempering of $\mathrm{Cr}-\mathrm{V}$ ledeburitic steels at the temperature around $500^{\circ} \mathrm{C}$ generally induces a hardness increase, commonly known as secondary hardening effect. It is connected with the precipitation of fine carbides from the martensite and the retained austenite, respectively, and with the transformation of retained austenite to the martensite during the cooling down from the tempering temperature. As pointed out elsewhere [8], the maximum secondary hardness peak of laser melted and rapidly solidified metals is shifted to higher tempering temperature. As the principal explanation, higher energy needed for the destabilization of retained austenite compared to furnace processed materials, was suggested. In addition, it should be mentioned that there is no presence of phases (for instance $\delta$-ferrite) in laser remelted Vanadis 6 steel, which could influence the secondary hardenability of the material in a negative way. The challenge for future experiments is then to perform the investigations of tempering behaviour of the laser remelted Vanadis 6 steel.

Additional softening of the material below the remelted area is also natural to be expected. This region contains also the retained austenite as the dominant constituent. But its supersaturation can be expected to be even much lower than that of remelted region.

The maximum hardness was found in the solid state hardened area. There is the structure with the fine needlelike martensite, small portion of retained austenite, and undissolved carbides, Figure 11. Such a structural type corresponds well to that developed but conventional furnace austenitizing and quenching, of course in a refined manner. High hardness of solid state hardened material is then logical.

In the vicinity of the laser spot, the hardness decreased again, as a result of so-called overtempering of the material. It can be believed that in narrow region around the laser spot, the temperature exceeded the tempering temperature of the material $\left(550^{\circ} \mathrm{C}\right)$ but did not reach to the austenitizing temperature. It is known that $\mathrm{Cr}-\mathrm{V}$ ledeburitic steels have the maximum secondary hardness peak at the tempering temperatures from the range $500-550^{\circ} \mathrm{C}$. Beyond this peak, the hardness drops down rapidly [17]. Measured values in

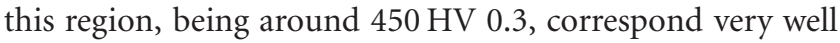
to these considerations.

\section{Conclusions}

Laser surface hardening with remelting has been carried out on the Vanadis 6 ledeburitic steel. The main findings can be summarized as follows.

Laser affected spot consists of four typical regions. In the centre, there are thin completely remelted and much larger partially remelted regions. Around, solid state hardened region and thin overtempered zones are located.

The microstructure of remelted region is formed with primary austenite cells and continuous eutectic network along them. Partially melted region contains undissolved MC-carbides, austenitic grains with certain portion of the martensite, and less or more continuous "degenereous eutectic" network based on the $\mathrm{M}_{7} \mathrm{C}_{3}$-carbides.

Solidification mechanism of laser completely melted material corresponds well to previous observations of the author, concerning the Fe-C-Cr-V quaternary alloys. If the material was not completely melted, then the solidification was restricted only to the formation of either standard $\mathrm{M}_{7} \mathrm{C}_{3}$ carbide/austenite eutectic or, if the temperature was even lower, to the so-called "degeneroeus" eutectic based on the same carbide.

Laser remelted material is significantly softer than that hardened in a solid state. Principal explanation can be given by the presence of dominant portion of retained austenite in the microstructure.

Low hardness in laser remelted region could be improved by subsequent tempering. Since the primary grains do not contain any phases that could restrict the capability of the material to be strengthened via precipitation, the investigation of the tempering behaviour of the laser melted Vanadis 6 steel is a challenge for the future investigations.

\section{References}

[1] P. R. Strutt, H. Nowotny, M. Tuli, and B. H. Kear, "Laser surface melting of high speed tool steels," Materials Science and Engineering, vol. 36, no. 2, pp. 217-222, 1978.

[2] P. Molian and H. Rajasekhara, "Laser melt injection of BN powders on tool steels I: microhardness and structure," Wear, vol. 114, no. 1, pp. 19-27, 1987.

[3] P. Jurči, P. Stolař, and I. Dlouhý, "Laser heat treatment of 6-5-2 high speed steels of different production way," in Proceedings of the 10th Congress of the IFHTE, T. Bell and R. J. Mittemeijer, Eds., vol. 25, Brighton, UK, 1996.

[4] H. Jones, "Modelling of growth and microstructure selection in rapid solidification: a progress report," Materials Science and Engineering A, vol. 133, pp. 33-39, 1991.

[5] P. F. Nizhnikowskaya, E. P. Kalinushkin, L. M. Snagovskij, and G. F. Demchenko, "Structural formation of high-speed 
steels during crystallization, Metallovedenie i Termicheskaya Obrabotka Metallov," Metal Science and Heat Treatment, vol. 24, no. 11, pp. 777-784, 1982.

[6] P. Jurči, O. Honzík, and P. Stolař, "Investigation of laser affected zones on the 19830-grade high speed steel," Metal Materials, vol. 33, p. 165, 1995.

[7] P. Jurči, "Surface remelting of ledeburitic steels by laser," Metal Letters, vol. 53, p. 12, 1998.

[8] R. Colaço and R. Vilar, "Effect of laser surface melting on the tempering behaviour of DIN X42Cr13 stainless tool steel," Scripta Materialia, vol. 38, no. 1, pp. 107-113, 1997.

[9] R. Colaço and R. Vilar, "Stabilisation of retained austenite in laser surface melted tool steels," Materials Science and Engineering A, vol. 385, no. 1-2, pp. 123-127, 2004.

[10] P. Jurči and P. Grgač, "Structural analysis of laser surface remelted CH3F12-alloy," in Proceedings of the International Conference of Technology, P. Kostka, Ed., Bratislava, Slovakia, September 1993.

[11] P. Jurči, F. Hnilica, J. Suchánek, and P. Stolař, "Microstructural features of $\mathrm{Cr}-\mathrm{V}$ ledeburitic steel saturated with nitrogen," Materials and Technology, vol. 38, p. 13, 2004.

[12] E. Ramous, "Rapid surface melting," Materials Science and Engineering A, vol. 178, no. 1-2, pp. 185-188, 1994.

[13] P. Jurči, Preparation and investigation of properties of rapidly solidified powders and compacts of the Fe-C-Cr-V - system, Ph.D. thesis, MtF STU, Trnava, Slovakia, 1996.

[14] P. Juřci, D. Vojtěch, and P. Stolař, "Influence of solidification conditions on microstructure and phase composition of a Fe4C-12Cr-13V alloy," Zeitschrift fuer Metallkunde/, vol. 88, no. 9, pp. 733-738, 1997.

[15] R. A. Versaci, "Stability of carbides in M2 high speed steel," Journal of Materials Science Letters, vol. 7, no. 3, pp. 273-275, 1988.

[16] K. Stiller, L. E. Svensson, P. R. Howell, W. Rong, H. O. Andrén, and G. L. Dunlop, "High resolution microanalytical study of precipitation in a powder metallurgical high speed steel," Acta Metallurgica, vol. 32, no. 9, pp. 1457-1467, 1984.

[17] P. Jurči, J. Sobotová, J. Cejp, P. Salabová, and O. Prikner, "Effect of sub-zero treatment on mechanical properties of the vanadis 6 PM ledeburitic tool steel," in Proceedings of the 19th International Metallurgical and Materials Conference (METAL '10), S. R. O. Tanger, Ed., Rožnov pod Radhoštěm, Czech Republic, May 2010. 

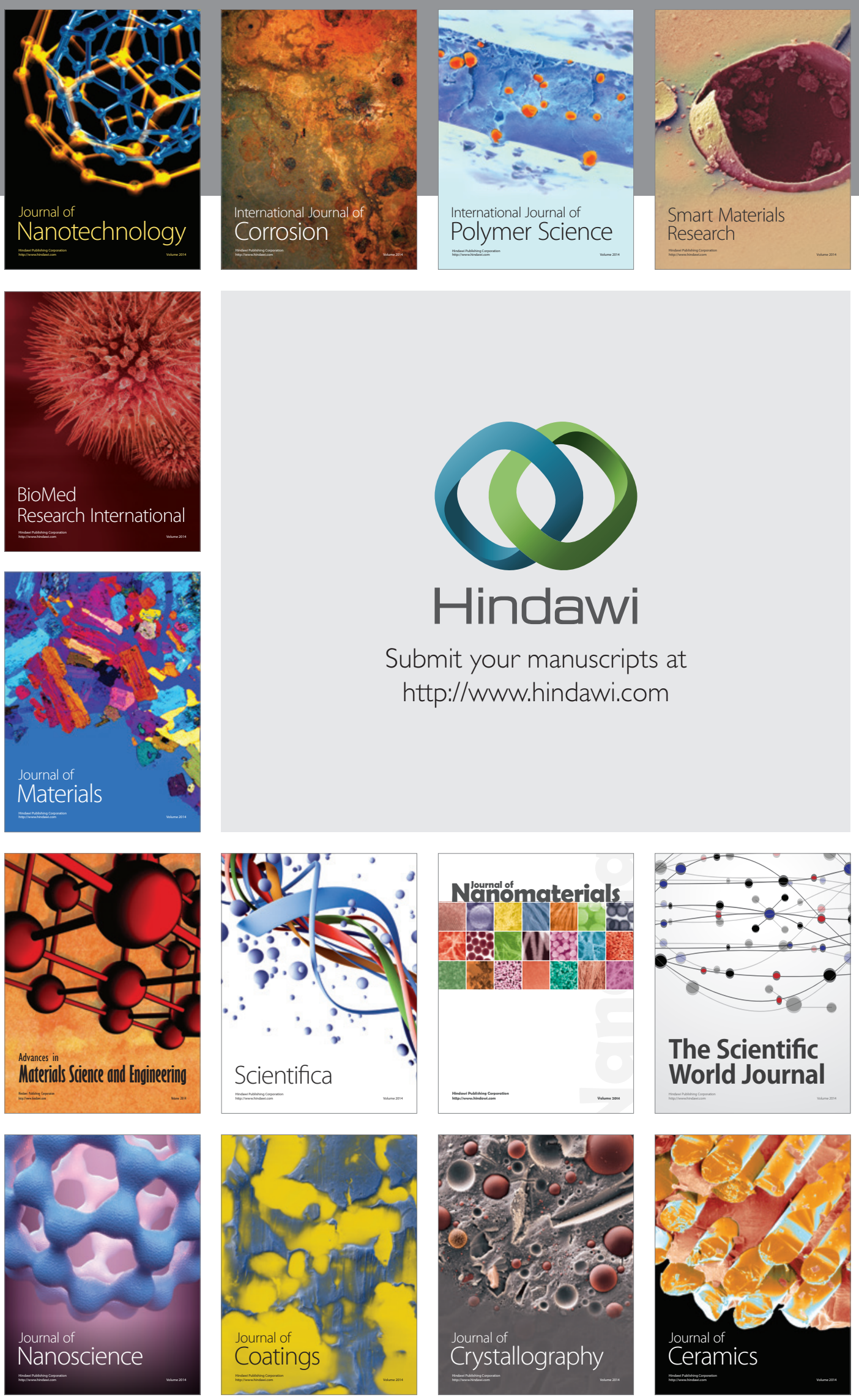

The Scientific World Journal

Submit your manuscripts at

http://www.hindawi.com

\section{World Journal}

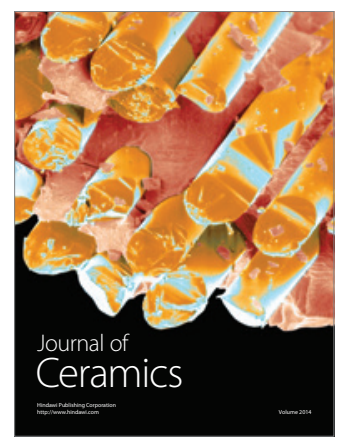

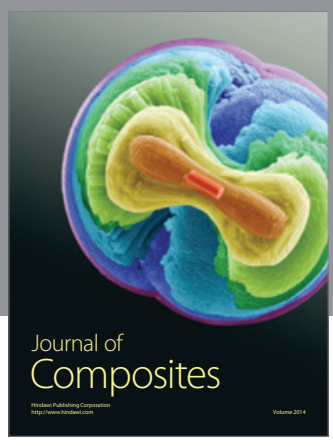
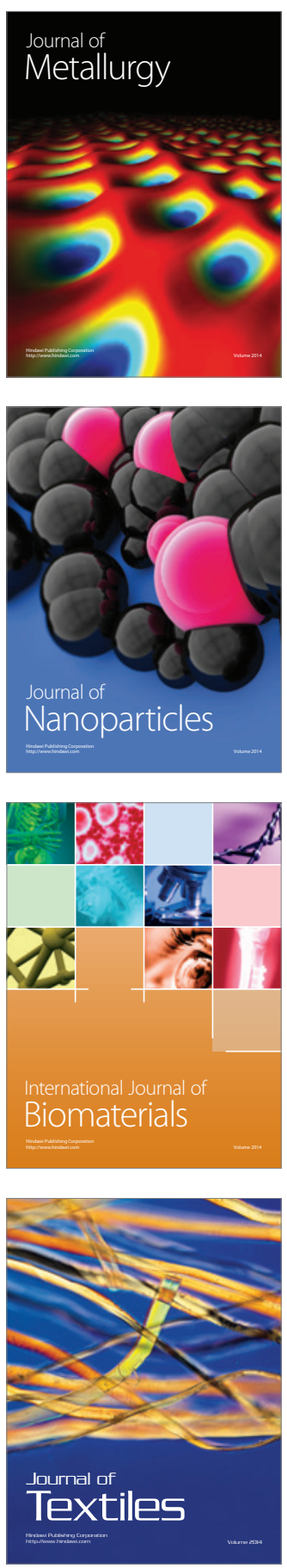